\title{
Inversion of magnetic measurements of the $C H A M P$ satellite over the Pannonian Basin
}

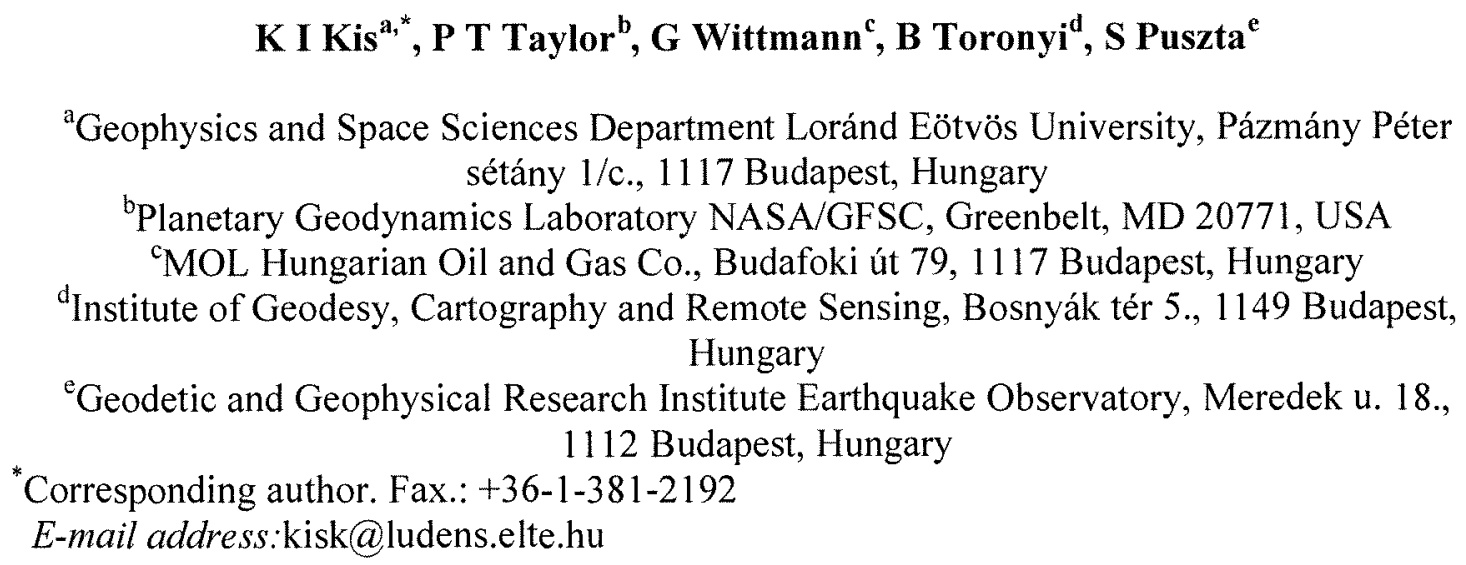

\section{Abstract}

The Pannonian Basin is a deep intra-continental basin that formed as part of the Alpine orogeny. In order to study the nature of the crustal basement we used the long-wavelength magnetic anomalies acquired by the CHAMP satellite. The anomalies were distributed in a spherical shell, some 107,927 data recorded between January 1 and December 31 of 2008. They covered the Pannonian Basin and its vicinity. These anomaly data were interpolated into a spherical grid of $0.5^{\circ} \times 0.5^{\circ}$, at the elevation of $324 \mathrm{~km}$ by the Gaussian weight function. The vertical gradient of these total magnetic anomalies was also computed and mapped to the surface of a sphere at $324 \mathrm{~km}$ elevation. The former spherical anomaly data at $425 \mathrm{~km}$ altitude were downward continued to $324 \mathrm{~km}$. To interpret these data at the elevation of $324 \mathrm{~km}$ we used an inversion method. A polygonal prism forward model was used for the inversion. The minimum problem was solved numerically by the Simplex and Simulated annealing methods; a $L_{2}$ norm in the case of Gaussian distribution parameters and $L_{1}$ norm was used in the case of Laplace distribution parameters. We INTERPRET THAT the magnetic anomaly WAS produced by several sources and the effect of the sable magnetization of the exsolution of hemo-ilmenite minerals in the upper crustal metamorphic rocks.

Keywords: CHAMP, Pannonian Basin, total and vertical gradient magnetic anomalies, downward continuation, inversion

\section{Introduction}

The Pannonian Basin extends some 800 by $500 \mathrm{~km}$ in a generally east-northeast direction with depths extending to $7 \mathrm{~km}$. Large crustal features produce long wavelength 
magnetic anomalies. These anomalies are sufficiently resolved by satellite altitude

43 observations. The German satellite CHAMP was launched on July 15, 2000 (Reigber et al.

442003,2005 ) and it finished its mission on September 19, 2010. This satellite measured the

45 gravity and magnetic field of the Earth with high accuracy. The total magnetic data are

46 obtained by a scalar Overhauser magnetometer developed by the Laboratorie d'Electronique

47 de Technologie et d'Instrumentation in Grenoble, France. The accuracy of the scalar magnetic

48 measurements was $\pm 0.5 \mathrm{nT}$ and these magnetic field data was recorded every second (Rother

49 et al. 2003).

$50 \quad$ CHAMP had a nearly circular, polar orbit its initial elevation of $456 \mathrm{~km}$ decreased due

51 to upper atmospheric drag and it was boosted several times. The elevation interval of the orbit

52 was between 319 and $340 \mathrm{~km}$ in 2008 . The magnetic anomalies used in the present paper had

53 been derived by the NASA by the application of the CHAOS2 model (Olsen et al. 2009).

\section{Interpolation and coordinate transformation}

The aim of our calculations is the reduction and interpretation of the magnetic anomalies over the Pannonian Basin and its vicinity (latitude, $38^{\circ}-52^{\circ}$ North; longitude, $14^{\circ}$ - $28^{\circ}$ East). The magnetic measurements are mapped on a spherical shell at $319-340 \mathrm{~km}$ elevation, and these data are given as a function of the latitude, longitude and elevation. The experimental frequencies of the latitude, longitude and elevation distributions of the recorded locations are plotted in Figure 1. As shown, they generally cover our study area. Data whose $K p$ index was less than or equal to $1_{-}$were selected for further processing. Using this criterion we obtained 107,927 data points. These data are interpolated into a spherical grid of $0.5^{\circ} \times 0.5^{\circ}$ at the elevation of $324 \mathrm{~km}$.

The Gaussian weight function of the $3 \mathrm{D}$ interpolation is

$$
w\left(\Delta_{i}, k\right)=\frac{\pi^{3 / 2}}{k^{3}} \exp \left(-\frac{\pi^{2}}{k^{2}} \Delta_{i}^{2}\right)
$$

where $k$ is the parameter of the weight function, $\Delta_{\mathrm{i}}$ is the distance between the $i$ th data observed and the single reference point of the spherical grid details are given by Véges (1971), Kis and Wittmann (1998), (2002). The interpolated value is normalized by the

73 following: 


$$
T^{\text {interpotated }}=\frac{1}{\sum_{i=1}^{n} w_{i}} \sum_{i=1}^{n} T_{i} w_{i}
$$

77 where $n$ is the number of data taken into consideration and $T_{i}$ is the $i$ th total magnetic anomaly

78 value. The interpolated total magnetic anomalies are plotted in Figure 2.

79 For the methods used in this study, the quantitative interpretation of the satellite 80 measured magnetic anomalies requires the transformation from a spherical to Cartesian

81 coordinates. The origin of the Cartesian coordinate system is $\varphi=47^{\circ}$ (latitude) and $\lambda=21^{\circ}$

82 (longitude) at an elevation of $324 \mathrm{~km}$. In accordance with the general usage in geomagnetism,

83 the coordinate axes $x$ and $y$ directed towards the North and East, respectively, while the $z$-axis

84 points downwards. The details of these computations are given in the Appendix A.

\section{Vertical derivative and downward continuation}

Vertical gradient anomalies show good correlation with the probable extension of the 89 geologic body (Blakely 1995). They qualitatively delineate the lateral extension of the 90 magnetic source. The determination of the vertical gradients is a linear transform; its transfer 91 function is given by:

$$
S\left(f_{x}, f_{y}\right)=2 \pi\left(f_{x}^{2}+f_{y}^{2}\right)^{1 / 2}
$$

95 where $f_{x}$ and $f_{y}$ are the spatial frequencies in the $x$ and $y$ axes (Blakely, 1995). It has long been 96 recognized that high frequency amplification is undesirable, since these frequencies possess 97 the lowest signal-to-noise level. In order to eliminate noise this transfer function is multiplied 98 by a two-dimensional Gaussian low-pass window:

$$
S_{L P}\left(f_{x}, f_{y}\right)=\exp \left(-k^{2}\left(f_{x}^{2}+f_{y}^{2}\right)\right)
$$

101

102 The parameter $k$ controls the passed frequency range. The weight function of this transform 103 is: 


$$
s(x, y)=\frac{\pi^{5 / 2}}{k^{3}} \exp \left(-\left(\frac{\pi^{2}\left(x^{2}+y^{2}\right)}{k^{2}}\right)\right) \mathrm{M}\left(-\frac{1}{2}, 1,\left(\frac{\pi^{2}\left(x^{2}+y^{2}\right)}{k^{2}}\right)\right),
$$

where $M$ means the confluent hyper-geometric function. The details of this transform are given by Kis and Puszta (2006). The vertical gradients of the total magnetic anomalies at the altitude of $324 \mathrm{~km}$ are plotted in Figure 3. A negative anomaly, with a minimum gradient of $0.01 \mathrm{nT} / \mathrm{km}$, covers the Pannonian Basin. The spatial shape of the vertical gradient anomaly

111 determines the extension of our model in the inversion procedures.

112 The downward continuation of the magnetic anomalies can also be expressed as a 113 linear transform. Its transfer function is:

$$
S_{\text {downward }}\left(f_{x}, f_{y}\right)=\exp \left(2 \pi h\left(f_{x}^{2}+f_{y}^{2}\right)^{1 / 2}\right)
$$

117 where $h$ is the downward continuation value. Different authors (Bullard and Cooper, 1948; De 118 Meyer, 1974) have suggested the application of an appropriate window for the computation of this transform. We used, however, Meskó (1984) for our procedure.

$$
S_{\text {downward }}\left(f_{x}, f_{y}\right)=\exp \left(2 \pi h\left(f_{x}^{2}+f_{y}^{2}\right)^{1 / 2}\right) \quad \text { for }\left(f_{x}^{2}+f_{y}^{2}\right)^{1 / 2} \leq f_{r c}
$$

$$
=\exp \left(2 \pi h\left(f_{x}^{2}+f_{y}^{2}\right)^{1 / 2}-\gamma\left(\left(f_{x}^{2}+f_{y}^{2}\right)^{1 / 2}-f_{r c}\right)\right) \quad \text { for }\left(f_{x}^{2}+f_{y}^{2}\right)^{1 / 2}>f_{r c} \text {. }
$$

123 This equation is our modified transfer function for the solution of the downward continuation.

124 From an earlier calculation we have the CHAMP total magnetic anomalies on the elevation of $125425 \mathrm{~km}$ (Taylor et al. 2005). We will use this as our base level for the downward continuation. 126 This transformation is used for the downward continuation plotted in Figure 4. The 127 parameters of the downward continuation are: average sampling interval $41.3 \mathrm{~km}, h$ depth of 128 downward continuation. The appropriate value of the parameters of $\gamma$ and $f_{r c}$ is 145 and 0.005 , 129 respectively. The anomalies at 425 and $324 \mathrm{~km}$ altitudes as well as the downward continued 130 anomalies are presented in Figure 4. The deviation between the calculated magnetic 131 anomalies and the downward continued anomalies is probably caused by the different depths 132 of the complex magnetic sources especially in the North-East part of the downwarded 133 anomalies, in the territory of the Carpathian Mts. 


\section{Model of inversion and Bayesian inference}

The magnetic anomaly map $(324 \mathrm{~km})$ reveals a large NW-SE oriented negative anomaly (-13 nT) in the middle of the Pannonian Basin (Figure 4). The qualitative

139 interpretation of this anomaly was given by Taylor et al. (2005), the reverse magnetization of

$140(-1.5 \mathrm{~A} / \mathrm{m})$ of the upper crust was the basis for their interpretation. The anomaly was forward 141 modeled by a triangular polygonal prism using Plouff's (1976) method. Our calculated 142 magnetic anomaly field $(324 \mathrm{~km})$ corresponds to the previous magnetic anomaly field (425 $143 \mathrm{~km}$ ) (Taylor et al. 2005).

144 The shape of the forward model and the magnetization are the same as they are in the 145 qualitative interpretation (Taylor et al. 2005). For the solution of the inverse problem the 146 magnetic anomaly of $324 \mathrm{~km}$ is used and the direction of the magnetization is $\alpha=-60^{\circ}, \beta=$ $14760^{\circ}, I=60^{\circ}$ and $D=0^{\circ}$, where $\alpha$ and $\beta$ are the inclination and declination of the 148 magnetization and $I$ and $D$ are the inclination and declination of the Earth magnetic field. 149 Model parameters are the top and bottom of the polygonal prism, and the three coordinate 150 pairs of the horizontal triangle (Figure 5).

151 An effective tool of the geophysical inversion is the Bayesian inference. The 152 mathematical basis and theory of the method are summarized, for example, by Box and Tiao 153 (1973) and Tarantola (1987); its geophysical application is given by Duijndam (1988a), 154 (1988b), Menke (1989), Sen and Stoffa (1995). The elements of the measured and model 155 vectors are indicated by $\mathbf{d}$ and $\mathbf{m}$; they are random variables.

156 The conditional probabilities in the applied Bayesian equation (Bayes, 1763) is

$$
p(\mathbf{m} \mid \mathbf{d})=p(\mathbf{d} \mid \mathbf{m}) p(\mathbf{m})
$$

where $p(\mathbf{m} \mid \mathbf{d})$ is the a posteriori conditional probability density, $p(\mathbf{d} / \mathbf{m})$ is the likelihood conditional probability density, and $p(\mathbf{m})$ is the a priori probability density.

162 The multivariate Gaussian a posteriori probability can be expressed as the 163 multiplication of the a priori and likelihood probability densities. Disregarding the constant 164 multipliers the a posteriori probability is given as: 


$$
p^{a \text { posteriori }} \propto \exp \left(-\frac{1}{2}\left(\mathbf{m}-\mathbf{m}^{a \text { priori }}\right)^{T} \mathbf{C}_{m}^{-1}\left(\mathbf{m}-\mathbf{m}^{a \text { priori }}\right)\right)
$$

$$
\cdot \exp \left(-\frac{1}{2}\left(\mathbf{d}^{\text {measured }}(x, y)-T^{\text {calculated }}(x, y, \mathbf{m})\right)^{T} \mathbf{C}_{D}^{-1}\left(\mathbf{d}^{\text {measured }}(x, y)-T^{\text {calculated }}(x, y, \mathbf{m})\right)\right)
$$

168 The $\mathbf{m}^{a \text { priori }}$ vector expresses the interpreter's decision to select the value of the model 169 parameters, $\mathbf{C}_{m}$ is the a priori covariance matrix superscript $T$ indicates the transpose vectors.

170 The variances in the matrix $\mathbf{C}_{m}$ express the uncertainty of the interpreter. $T^{\text {calculated }}(x, y, \mathbf{m})$ 171 represents the calculated magnetic direct problem with the parameters $\mathbf{m}$ at the $x, y$ 172 coordinates. $\mathbf{C}_{D}$ is the data covariance matrix. It consists of two parts (1) the measurements 173 uncertainty matrix $\mathbf{C}_{d}$ (the measurements variances), and (2) the model error matrix $\mathbf{C}_{T}$, 174 namely

$$
\mathbf{C}_{D}=\mathbf{C}_{d}+\mathbf{C}_{T}
$$

The elements of the model error matrix are also determined by the interpreter. This matrix contains the goodness of the selected model.

The model parameter values of the source can be determined by the solution of an optimum problem. It means maximizing the a posteriori probability density as a function of m. This is equivalent to minimizing the sum of exponents of the Equation (9). The objective function $E(\mathbf{m})$ has the following form of

$$
E(\mathbf{m})=\left(\left(\mathbf{m}-\mathbf{m}^{a \text { priori }}\right)^{T} \mathbf{C}_{m}^{-1}\left(\mathbf{m}-\mathbf{m}^{a \text { priori }}\right)\right)+
$$

$$
+\left(\left(\mathbf{d}^{\text {measured }}(x, y)-T^{\text {calculated }}(x, y, \mathbf{m})\right)^{T} \mathbf{C}_{D}^{-1}\left(\mathbf{d}^{\text {measured }}(x, y)-T^{\text {calculated }}(x, y, \mathbf{m})\right)\right) .
$$

$$
\mathbf{C}_{m}^{\prime} \approx\left(\mathbf{G}_{n}^{T} \mathbf{C}_{D}^{-1} \mathbf{G}_{n}+\mathbf{C}_{m}^{-1}\right)^{-1}
$$




$$
\mathbf{G}_{n}=\left(\frac{\partial T}{\partial \mathbf{m}}\right)_{\mathbf{m}=\mathbf{m}_{n}}
$$
following:

$$
p^{a \text { possteriori }} \propto \exp \left(-\frac{\left|\mathbf{m}-\mathbf{m}^{\text {apriori }}\right|}{\mathbf{C}_{m}^{1 / 2}}\right) \cdot \exp \left(-\frac{\left|\mathbf{d}^{\text {measured }}(x, y)-T^{\text {calculated }}(x, y, \mathbf{m})\right|}{\mathbf{C}_{D}^{1 / 2}}\right),
$$

where we disregard the constant multipliers. The objective function is expressed by the equation:

$$
E(\mathbf{m})=\left(\frac{\left|\mathbf{m}-\mathbf{m}^{a \text { priori }}\right|}{\mathbf{C}_{m}^{1 / 2}}\right)+\left(\frac{\left|\mathbf{d}^{\text {measured }}(x, y)-T^{\text {calculated }}(x, y, \mathbf{m})\right|}{\mathbf{C}_{D}^{1 / 2}}\right) .
$$

The minimum problem is solved by the Simplex (Walsh, 1975) and Simulated annealing (Kirkpatrik et al. 1983, Sen and Soffa 1995) methods. The minimum problems are solved by $L_{2}$ norm in the case of the Gaussian probability and by $L_{1}$ norm in the case of the Laplace probability. Figures 6 and 7 show the objective functions versus iterative steps. These figures illustrate how these two optimum procedures work. The parameters estimated by the former numerical methods are summarized in Table 1. The covariance matrices are diagonal;

213 there are no correlations between the related parameters. The a priori variances are set to (5 $214 \mathrm{nT})^{2}$, variances of the measured data are set to $(0.5 \mathrm{nT})^{2}$. Because the complex structure of the direct problem the elements of the a posteriori covariance matrix are approximated by difference quotients of Equation (13).

Figure 8 shows those residual anomalies that determine the application of the 218 parameters given in Table 1. The residuals in the four parts of the figure are calculated for 219 Gaussian and Laplace parameter distributions determined by Simplex and Simulated annealing methods. It can be concluded that the lowest residuals are given by the Laplace distribution parameters obtained by the Simulated annealing method. 
Large amplitude magnetic anomalies have been mapped by aircraft and satellites over regions of the Earth and by satellite over the Martian crust. Many of these anomalies have

227 negative signs. For our geological interpretation we call upon analogous source regions such 228 as the Mid-Proterozoic granulites in southwestern Sweden (McEnroe et al. 2001); Proterozoic

229 Ana Sira anorthosite in Rogaland, Norway (Robinson et al. 2002, McEnroe et al. 2004, 2005)

230 and the metamorphic complex in Modum district, Southern Norway (Fabian et al. 2008).

231 The magnetic properties of these rocks have been investigated by the above mentioned 232 authors. They suggest that the stable remanent magnetization is caused by the exsolution of 233 the hematite-ilmenite minerals. This exsolution can produce stable ferrimagnetism which is 234 investigated by model calculation (Robinson et al. 2002) and transmission electron 235 microscopy analysis (McEnroe et al. 2005). These analyses show $1 \mu \mathrm{m}$ to $4 \mathrm{~nm}$ exsolution of 236 both hematite lamella in ilmenite hosts and ilmenite lamella in hematite hosts. The contact 237 zone of these minerals can produce strong ferromagnetic effect which belongs to neither 238 hematite nor ilmenite source rocks.

239 According to Kleteschka et al. (2002) stable remanent magnetization can be developed 240 in the hemo-ilmenite minerals. The remanent magnetization is formed in the cooling process. 241 The anti-ferromagnetic hemo-ilmenite lamellas have multi-domain structures. They are able 242 to form intense thermo-remanent magnetization. This process can be more intensive in the 243 exsolution of hematite-ilmenite minerals.

244 Is this kind of magnetization found in the crust of the Pannonian Basin? The deep 245 magnetic sources are located in the upper crust; they probably belong to the eastern part of 246 Variscan Europe (Szederkényi 1996, Tari and Pamić 1998). The granulite xenoliths and 247 peridotite xenoliths obtained from the Pliocene basaltic rocks located in the Balaton 248 Highlands (Pelso-unit, part of the African Alcapa block). These granulite and peridotite 249 xenoliths discovered in these locations show crustal and upper mantle origins as suggested by 250 Embey-Isztin et al. (2003) and Dobosi et al. (2003). According to the thermo-barometric 251 investigations of these xenoliths they formed at a temperature of $800-900^{\circ} \mathrm{C}$ and at pressures 252 of $8-15 \mathrm{kbar}(0.8$ to $15 \mathrm{GPa})$. These meta-volcanic xenoliths have apparently formed at a 253 depth of 40-50 km. This depth is significantly deeper than the present $25-30 \mathrm{~km}$ thick crust. 254 The present crust was developed in the Tertiary due to the NW-SE extension of the 255 Pannonian Basin (Konečný et al. 2002). The alkaline basaltic rocks were formed in the 
256 Pliocene after the intense widespred Miocene calc-alkaline volcanism (Embey-Isztin et al. 257 2001).

258 The international literature discusses a few other possible solutions for source of large 259 negative magnetic anomalies. Due to the unknown parameters of the source rock in the upper 260 crust like age or direction of its magnetization, as well as accurate composition of this rock 261 we can not propose proven fact for the source. But the granulite xenoliths and peridotite 262 xenoliths obtained from the Pliocene basaltic rocks located in the Pannonian Basin give light 263 evidence of the significant part of the negative anomaly presented in this study is derived to 264 the exsolution of hematite-ilmenite minerals.

\section{Conclusions}

The total magnetic field, vertical gradient and downward continued anomalies indicate a magnetic low over the Pannonian Basin. Our inversion method determined that the source region was in the upper crust of the basin. We propose that the strong magnetization can be produced in the crust of the Pannonian Basin. The CHAMP magnetic anomaly can be explained by the exsolution of hemo-ilmenite minerals. It has been previously reported that hematite-ilmenite mineralogy can produce stable remanent magnetization in the crust and in our study we propose that the crustal rocks of the Pannonian Basin display negative remanent magnetization. We further propose that some of the magnetic source bodies were formed during the late Miocene-Pliocene tectonic activity of compression and extension and/or volcanism (Hámor, 2001) and emplaced in the upper crust.

\section{Appendix A} coordinates to Cartesian $x y z$ coordinate system. This transformation can be done in two steps: one translation and rotation.

287 Earth's rotation axis and points upward. The $Y$-axis is also in the plane of the equator and 288 perpendicular to the $X Z$ sheet and points to East. The $X, Y$, and $Z$ coordinates of the satellite 289 data are: 


$$
X=r \sin \theta \cos \lambda, \quad Y=r \sin \theta \sin \lambda, \quad Z=r \cos \theta,
$$

where $r$ is the distance from the center of the Earth, $\theta$ and $\lambda$ are the colatitude and longitude, 294 respectively.

Let us translate the origin of the $x^{\prime} y^{\prime} z^{\prime}$ Cartesian coordinate system in the central point $\left(r_{0}, \theta_{0}, \lambda_{0}\right)$, where $r_{0}=$ Earth's radius + altitude of the satellite. The $x^{\prime}, y^{\prime}$, and $z^{\prime}$ axes are parallel to the $X, Y$, and $Z$ axes. The $t_{x}, t_{y}$, and $t_{z}$ coordinates of this point in the $X Y Z$ coordinate system are

$$
t_{x}=r_{0} \sin \theta_{0} \cos \lambda_{0}, \quad t_{y}=r_{0} \sin \theta_{0} \sin \lambda_{0}, \quad t_{z}=r_{0} \cos \theta_{0}
$$

The equations of translation are:

$$
x^{\prime}=X-t_{x}, \quad y^{\prime}=Y-t_{y}, \quad z^{\prime}=Z-t_{z} .
$$
downward. The equations of rotation are:

$$
\begin{aligned}
& x=-x^{\prime} \cos \theta_{0} \cos \lambda_{0}-y^{\prime} \cos \theta_{0} \sin \lambda_{0}+z^{\prime} \sin \theta_{0} \\
& y=-x^{\prime} \sin \lambda_{0}-y^{\prime} \cos \lambda_{0} \\
& z=-x^{\prime} \sin \theta_{0} \cos \lambda_{0}-y^{\prime} \sin \theta_{0} \sin \lambda_{0}+z^{\prime} \cos \theta_{0} .
\end{aligned}
$$

\section{Acknowledgement}

Dr. Michael Purucker (Raytheon STX Corporation, NASA/GSFC) aided in obtaining these data which were kindly provided by the GFZ, POTSDAM, GERMANY. Mr. Terry J. Sabaka

317 constructive comments.

\section{References}


321 Bayes, T., 1773. An essay towards solving a problem in the doctrine of chances, Phil. Trans.

322 Roy. Soc. 53, 370-418 (republished in Biometrika, 45 (1958) 293-315).

323 Blakely, R. J., 1995. Potential Theory in Gravity and Magnetic Applications, Cambridge 324 University Press.

325 Box, G. E. P., Tiao, G. C., 1973. Bayesian Inference in Statistical Analysis, Addison-Wesley

326 Publishing Company, London, Don Mills, Reading, Menlo Park.

327 Bullard, E. C., Cooper, R. I. B., 1948. Determination of the masses necessary to produce a 328 given gravitational field, Proc. Roy. Soc. of London, A 194, 332-347.

329 De Meyer, F., 1974. Filter techniques in gravity interpretation, Adv. Geophys. 17, 187--261.

330 Dobosi, G., Kempton, P. D., Downes, H., Embey-Isztin, A., Thirlwall, M., Greenwood, P., 331 2003. Lower crustal granulite xenoliths from the Pannonian Basin, Hungary, Part 2: Sr-Nd$332 \mathrm{~Pb}-\mathrm{Hf}$ and $\mathrm{O}$ isotope evidence for formation of continental lower crust by tectonic 333 emplacement of oceanic crust, Contrib. Mineral. Petrol. 144, 671-683.

334 Duijndam, A. J. W., 1988a. Bayesian estimation in seismic inversion. Part I: Principles, 335 Geophys. Prosp. 36, 899-918.

336 Duijndam, A. J. W., 1988b. Bayesian estimation in seismic inversion. Part II: Uncertainty 337 analysis, Geophys. Prosp. 36, 878-898.

338 Embey-Isztin, A., Dobosi, G., Altherr, R., Meyer, H-P., 2001. Thermal evolution of the 339 lithosphere beneath the western Pannonian Basin: evidence from deep-seated xenoliths, 340 Tectonophysics 331, 283-305.

341 Embey-Isztin, A., Downes, H., Kempton, P. D., Dobosi, G., Thirlwall, M., 2003. Lower 342 crustal granulite xenoliths from the Pannonian Basin, Hungary. Part 1: mineral chemistry, 343 thermobarometry and petrology, Contrib. Mineral. Petrol. 144, 652-670.

344 Fabian, K., McEnroe, S. A., Robinson, P., Shcherbakov, V. P., 2008. Exchange bias 345 identifies lamellar magnetism as the origin of the natural remanent magnetization in 346 titanohematite with ilmenite exsolution from Modum, Norway, Earth Planet. Sci. Lett. 268, 347 339-353.

348 Hámor, G., 2001. Genesis and evolution of the Pannonian Basin, in: J. Haas (Ed), Geology of 349 Hungary, Eötvös University Press, Budapest, 193-242.

350 Kirkpatrick, S., Gelatt Jr. C. D., Vecchi, M. P., 1983. Optimization by simulated annealing, 351 Science $220,671-680$.

352 Kis, K. I., Puszta, S., 2006. Application of the magnetic field derivatives for locating 353 Sarmatian graves, J. Appl. Geophys. 60, 13-26. 
354 Kis, K. I., Wittmann, G., 1998. Determination of vertical magnetic anomalies and equivalent 355 layer for the European region from the Magsat measurements, J. Appl. Geophys. 39, 11-24.

356 Kis, K. I., Wittmann, G., 2002. 3D reduction of satellite magnetic measurements to obtain 357 magnetic anomaly coverage over Europe, J. Geodyn. 33, 117-129.

358 Konečný, V., Kovač, M., Lexa, J., Šefara, J., 2002. Neogene evolution of the Carpatho-

359 Pannonian region: an interplay of subduction and back-ark diapiric apprise in the mantle, 360 EGU Stephan Mueller Special Publication Series I, 105-123.

361 Kletetschka, G., Wasilewski, P. J., Taylor, P. T., 2002. The role of hematite-ilmenite solid 362 solution in the production of magnetic anomalies in ground and satellite-based data, 363 Tectonophysics, 347, 166-177.

364 McEnroe, S. A., Harrison, R. J., Robinson, P., Golla, U., Jercinovic, M. J., 2001. Effect of 365 fine-scale microstructures in titanohematite on the acquisition and stability of natural 366 remanent magnetization in the granulite facies metamorphic rocks, southwest Sweden: 367 Implications for crustal magnetism, J. Geophys. Res., 106 B12, 30,523-30,546.

368 McEnroe, S. A., Langenhorst, F., Robinson, P., Bromiley, G. D., Shaw, C. S. J., 2004. What 369 is magnetic in the lower crust? Earth Planet. Sci. Lett. 226, 175-192.

370 McEnroe, S. A., Harrison, R. J., Jackson, M. J., Hirt, A. M., Robinson, P., Langenhorst, F., 371 Heidelbach, F., Kasama, T., Putnis, A., Brown, L. L., Golla-Schindler, U., 2005. Lamellar 372 magnetism: Effects of interface versus exchange interactions of nanoscale exsolutions in 373 ilmenite-hematite system, J. Phys. Conference Series, 17, 154-167.

374 Menke, W., 1989. Geophysical Data Analysis: Discrete Inverse Theory, Academic Press, Inc. 375 San Diego, New York, Boston, Sydney, Tokyo, Toronto.

376 Meskó, A., 1984. Digital Filtering: Applications in Geophysical Exploration for Oil, 377 Akadémiai Kiadó, Budapest.

378 Olsen, N., Mandea, M., Sabaka, T. J., Tøffner-Clasen, L., 2009. CHAOS-2 a geomagnetic 379 field model derived from one decade of continuous satellite data, Geophys. J. Int., 179, 14773801487.

381 Plouff, D., 1976. Gravity and magnetic fields of polygonal prism and application to magnetic 382 terrain corrections, Geophysics 41, 727-741.

383 Reigber, C., Lühr, H., Schwintzer, P., (Eds.), 2003. First CHAMP Mission Results for 384 Gravity, Magnetics and Atmospheric Studies, Springer-Verlag, Berlin.

385 Reigber, C., Lühr, H., Schwintzer, P., Wickert, J., (Eds), 2005. Earth Observations with 386 CHAMP Results from Three Years in Orbit. Springer-Verlag, Berlin. 

in the hematite-ilmenite series as an explanation for strong remanent magnetization, Nature, $389418,517-520$.

390 Rother, M., Choi, S., Lühr, H., Mai, W., 2003. CHAMP ME data Processing and Open Issues, 391 in: C. Reigber, H. Lühr, P. Schwintzer, P. (Eds.), First CHAMP Mission Results For Gravity, 392 Magnetics and Atmospheric Studies, Springer-Verlag, Berlin.

393 Sen, M., Stoffa, P. L., 1995. Global Optimization Methods in Geophysical Inversion, 394 Elsevier, Amsterdam, Lausanne, New York, Oxford, Shannon, Tokyo.

395 Szederkényi, T., 1996. Metamorphic formations and their correlation in the Hungarian part of 396 the Tisia Megaunit (Tisia Composite Terrane), Acta Mineralogie-Petrographica. Szeged, 37, 397. $143-160$.

398 Tarantola, A., 1987. Inverse Problem Theory, Elsevier, Amsterdam, Oxford, New York, 399 Tokyo.

400 Tari, V., Pamić, J., 1998. Geodynamic evolution of the northern Dinarides and southern part 401 of the Pannonian Basin, Tectonophysics 297, 269-281.

402 Taylor, P. T., Kis, K. I., von Frese, R. R. B., Korhonen, J. V., Wittmann, G., Kim, H. R., 403 Potts, L. V., 2005. Effects of varying crustal thickness on CHAMP geopotential data, in: 404 Reigber, Ch., H. Luhr, J. Schwintzer, (Eds.), Earth Observation with CHAMP, Springer405 Verlag, Berlin, Heidelberg, New York, 279-286.

406 Véges, I., 1971. Map plotting with weighted average on the surface of a circular disc, Pure 407 Appl. Geophys. 78, 5-17.

408 Walsh, G. R., 1975. Methods of Optimization, John Willey \& Sons, London, New York, Sydney, Toronto.

\section{Captions}

Figure 1. Experimental frequency of the CHAMP magnetic anomalies versus latitude, 414 longitude and altitude over the Pannonian Basin and vicinity.

416 Figure 2. The CHAMP total magnetic anomaly map determined by interpolation of data from 417 the Pannonian Basin region, plotted on an Albers' projection at $324 \mathrm{~km}$ altitude; anomalies 418 are in $\mathrm{nT}$ with a range of 22 grey levels and a contour interval of $1 \mathrm{nT}$, inner frame shows the 419 investigated territory. 
421 Figure 3. The vertical gradient map of the CHAMP total magnetic anomaly field, plotted in 422 Albers' projection at the altitude of $324 \mathrm{~km}$; anomalies in $\mathrm{nT} / \mathrm{km}$ with a 14 grey scale levels 423 and a contour interval of $0.005 \mathrm{nT} / \mathrm{km}$, inner frame shows the investigated territory.

425 Figure 4. CHAMP magnetic anomaly maps at (a) $425 \mathrm{~km}$ and (b) $324 \mathrm{~km}$ altitude; (c) 426 downward continued magnetic anomaly map from $425 \mathrm{~km}$ to $324 \mathrm{~km}$, the maps are plotted on 427 Albers' projection; grey scale units in $\mathrm{nT}$.

429 Figure 5. Three dimensional triangular model of the magnetic source body we used in the 430 inverse problem, upper and lower depths are indicated by: $z_{T}$ and $z_{B}$, respectively, the 431 triangular base is given by three coordinate pairs: $\left(x_{1}, y_{1}\right),\left(x_{2}, y_{2}\right)$ and $\left(x_{3}, y_{3}\right)$.

433 Figure 6. Logarithm of the objective functions determined by Simplex method versus iterative 434 steps in the case of the Gaussian and Laplace distribution model parameters.

436 Figure 7. Logarithm of the objective functions determined by Simulated annealing method 437 versus iterative steps in the case of the Gaussian and Laplace distribution model parameters.

439 Figure 8. Residual anomalies in the case of the Gauss and Laplace distributed model 440 parameters when the minimum problem is solved by Simplex and Simulated annealing 441 methods; anomalies are in $\mathrm{nT}$ unit in a gray scale, horizontal coordinates are given in $\mathrm{km}$.

443 Table 1. Determined parameters by Simplex and Simulated annealing methods in the case of 444 the Gaussian and Laplace parameter distributions. 

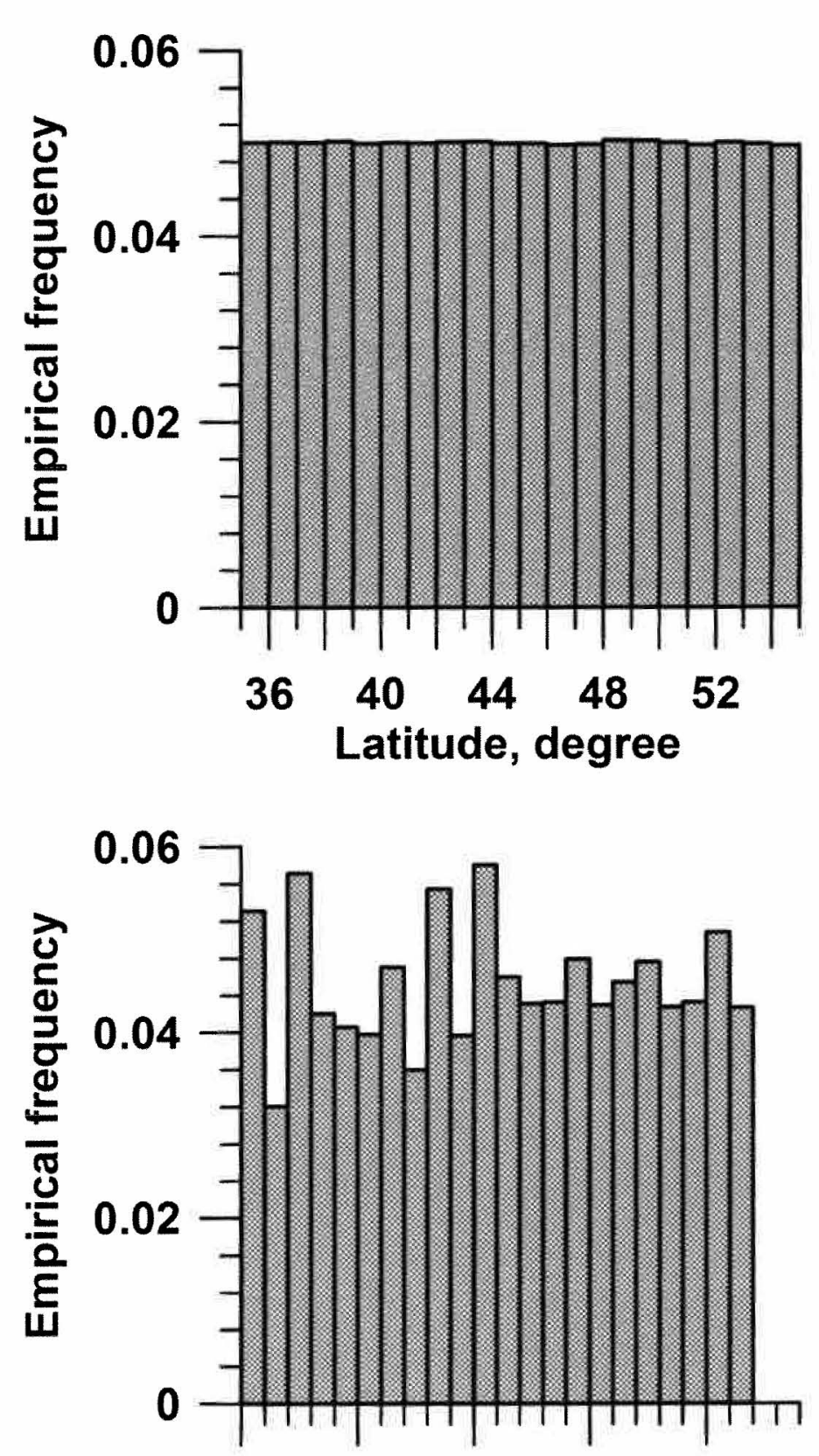

$\begin{array}{lllll}10 & 15 & 20 & 25 & 30\end{array}$

Longitude, degree

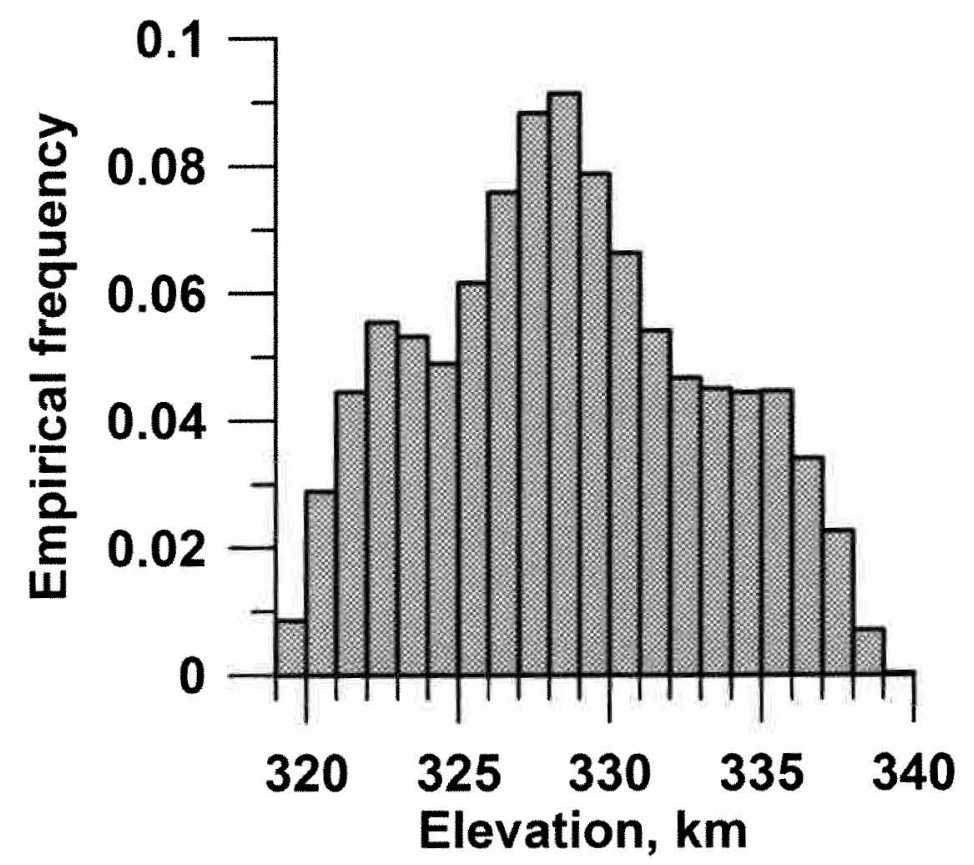



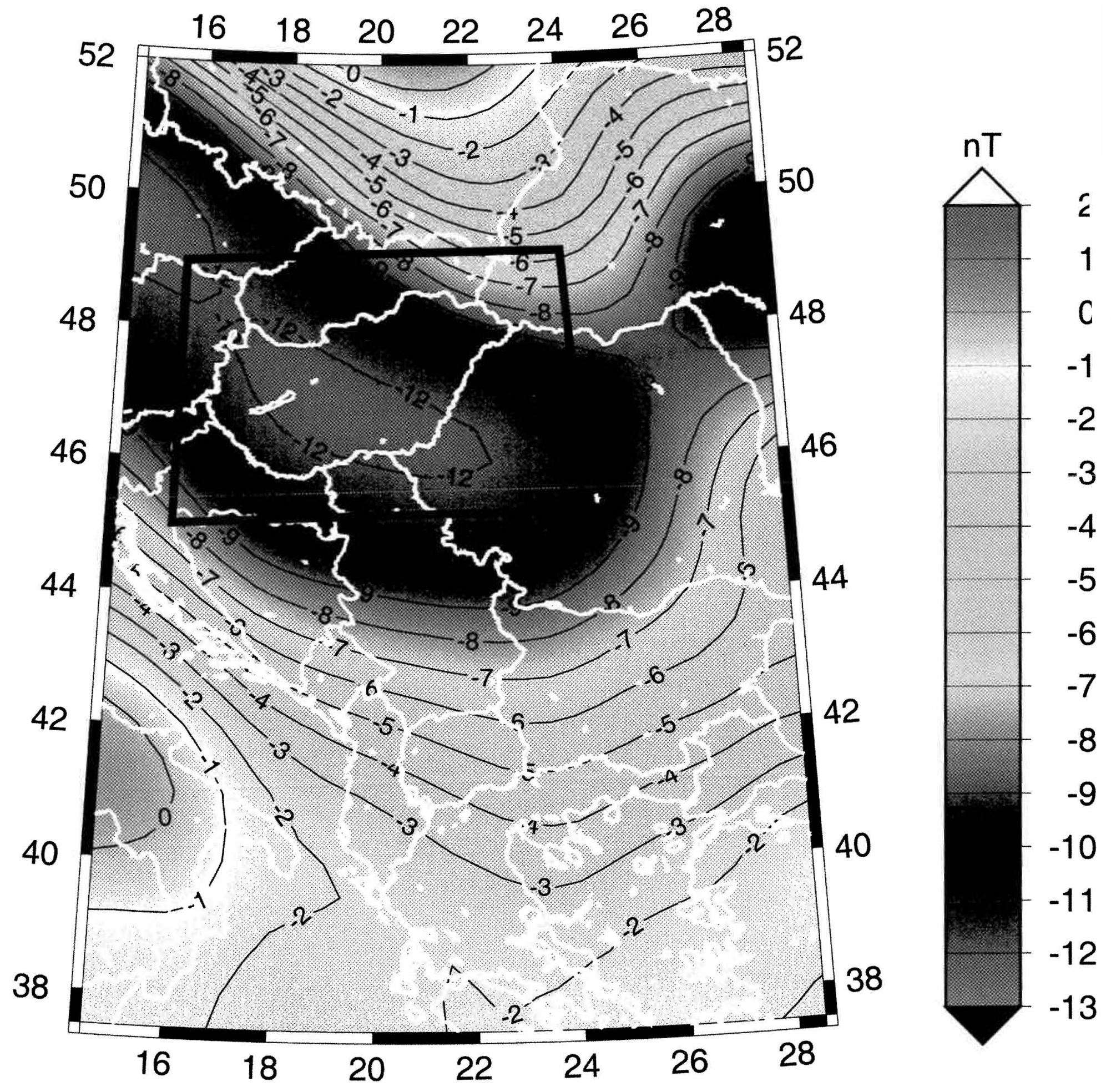


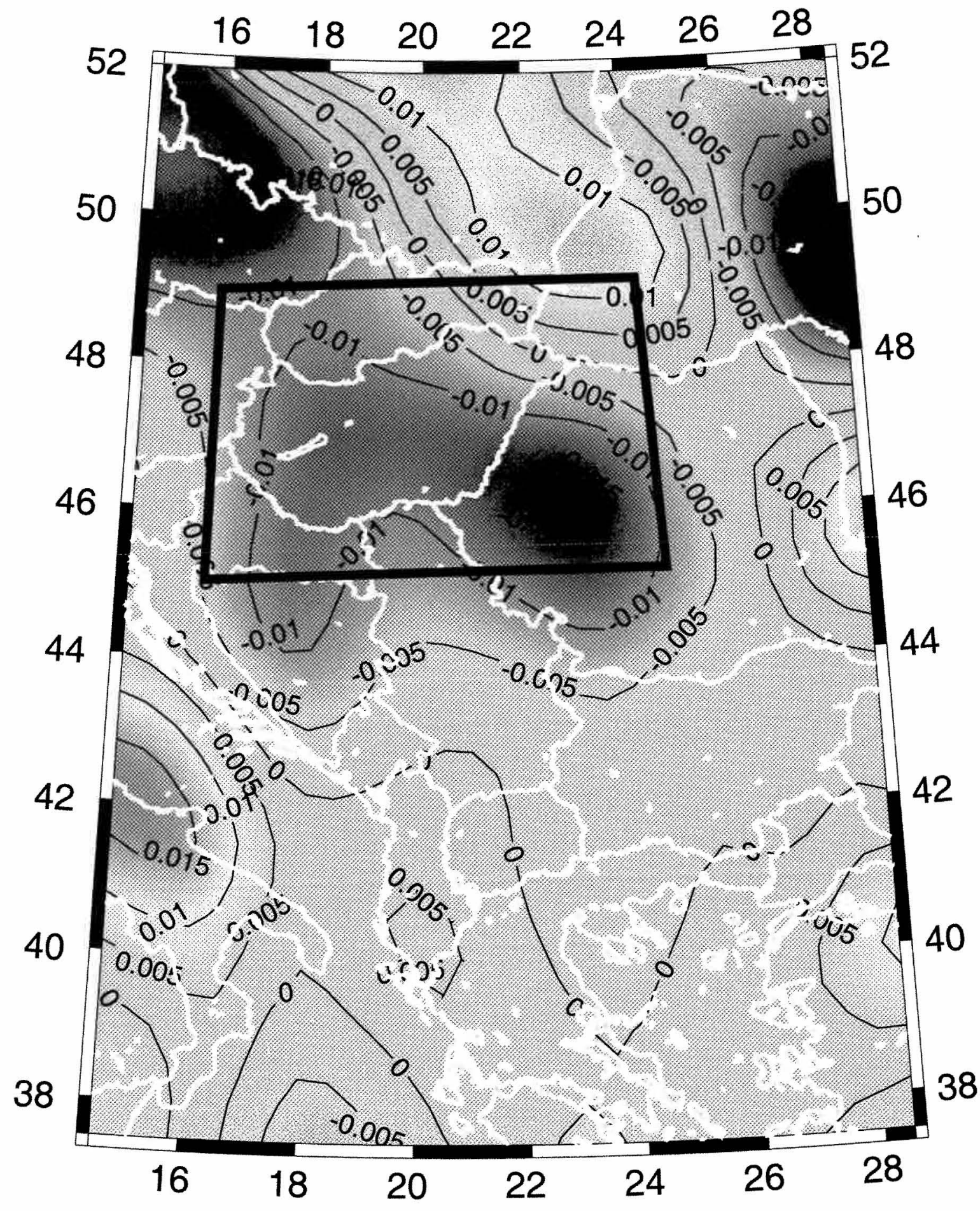

$\mathrm{nT} / \mathrm{km}$

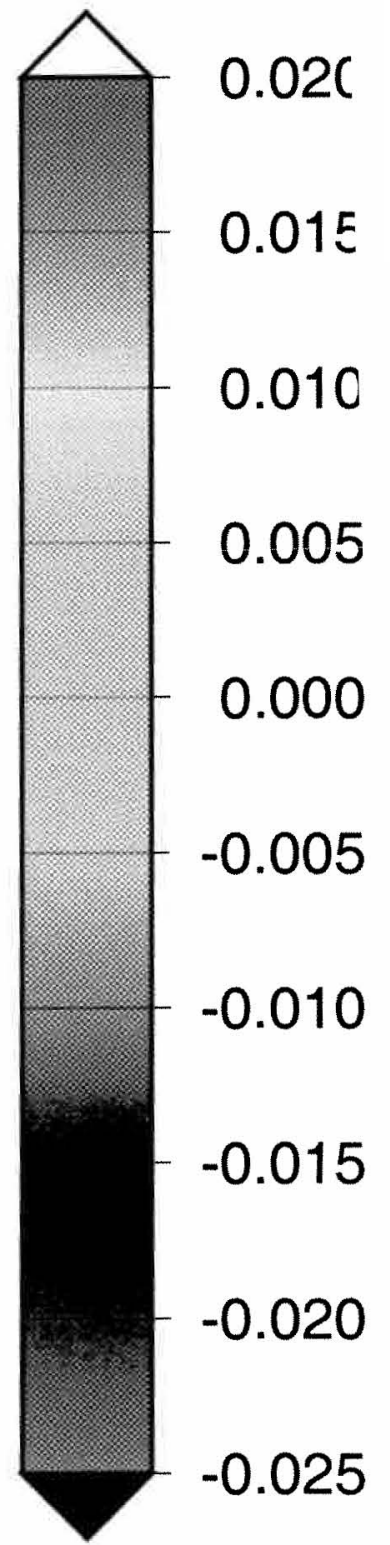



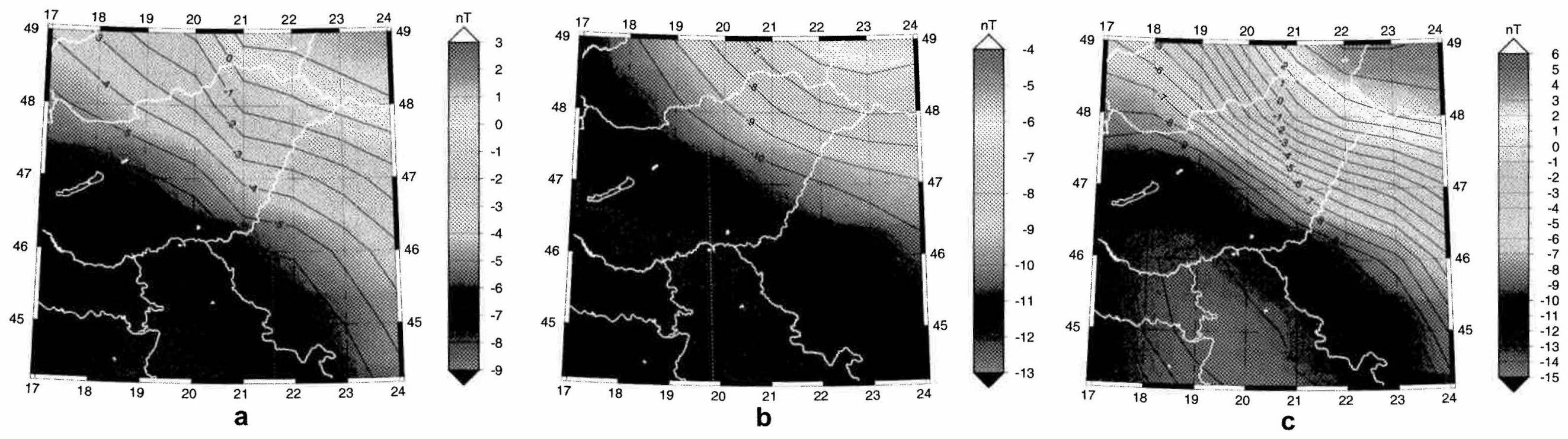


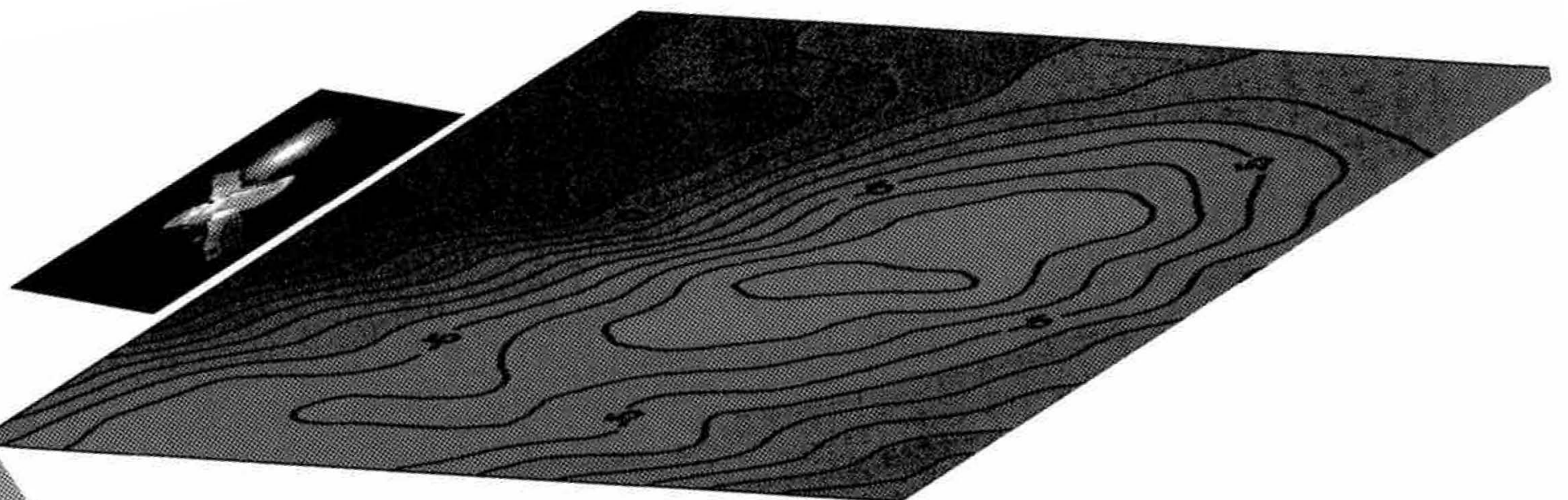

$324 \mathrm{~km}$

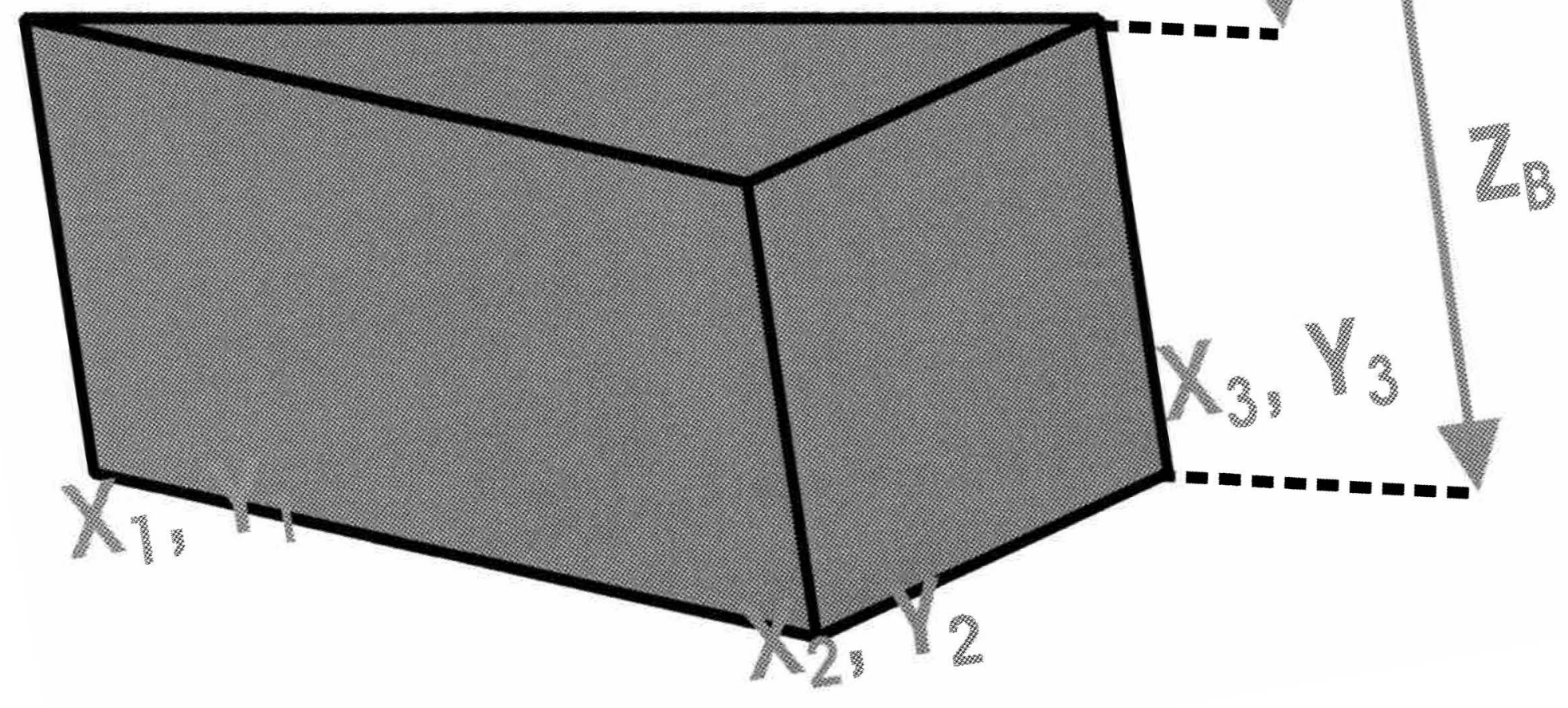




\section{Simplex method}

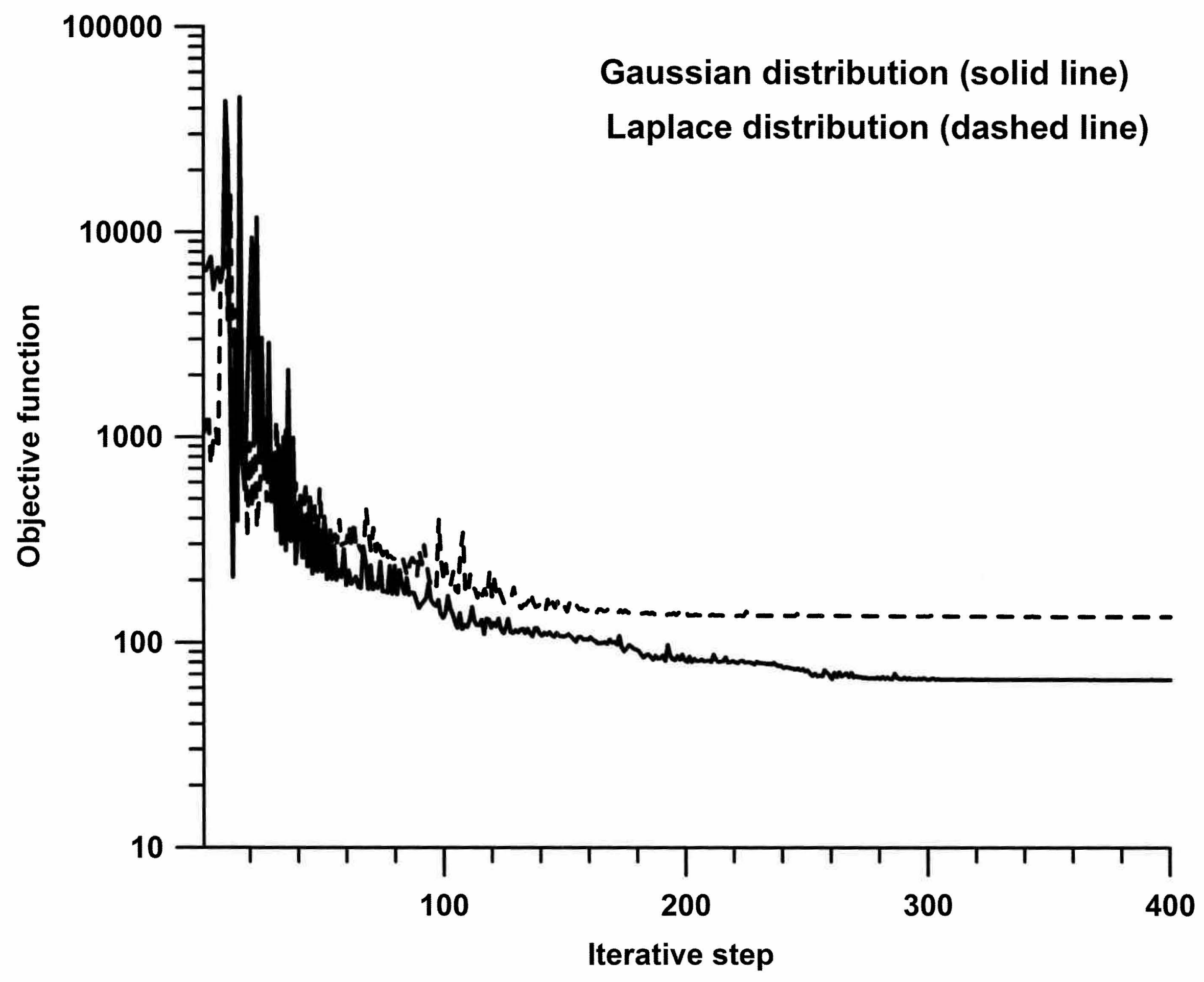




\section{Simulated annealing method}

Gaussian distribution (solid line)

Laplace distribution (dashed line)

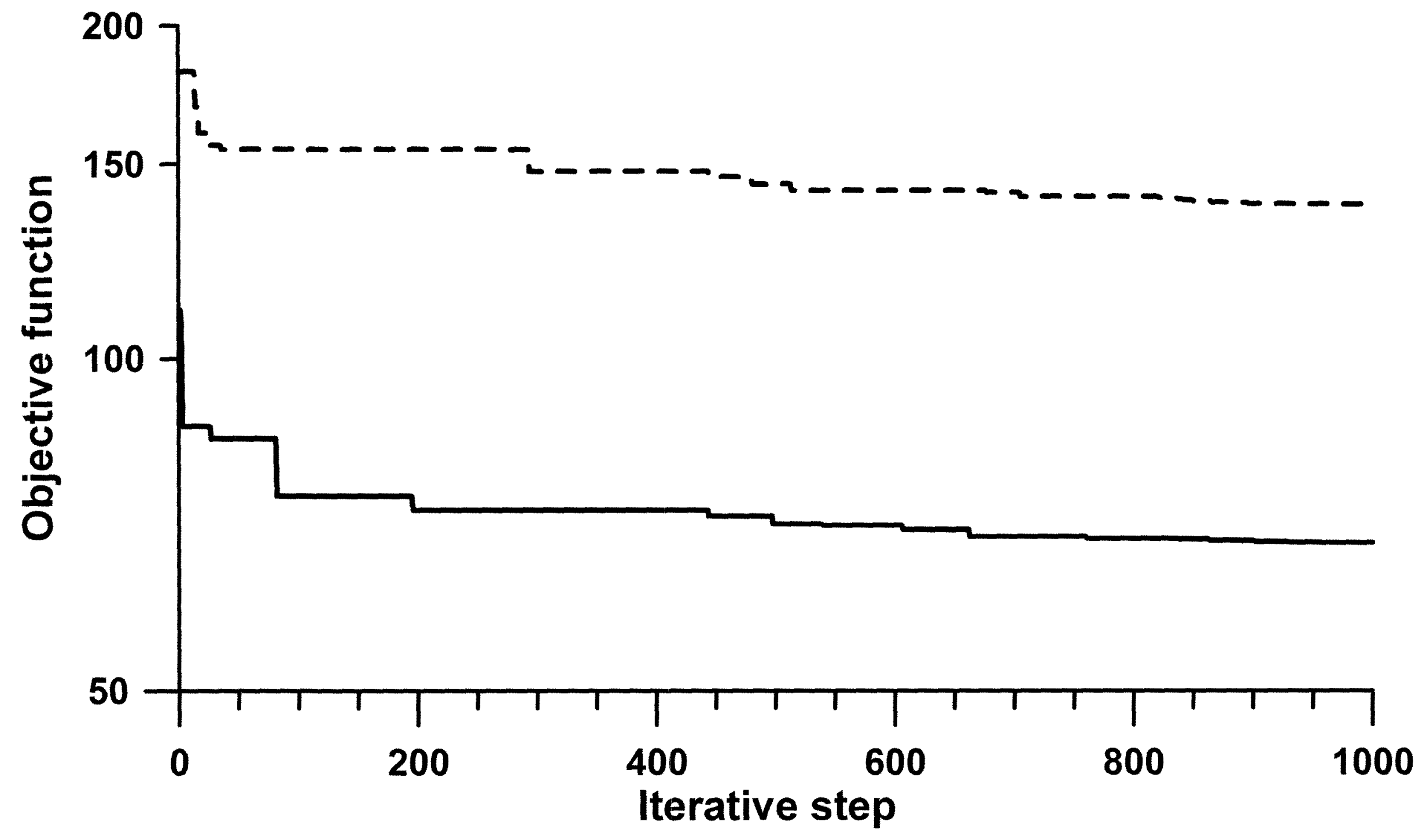



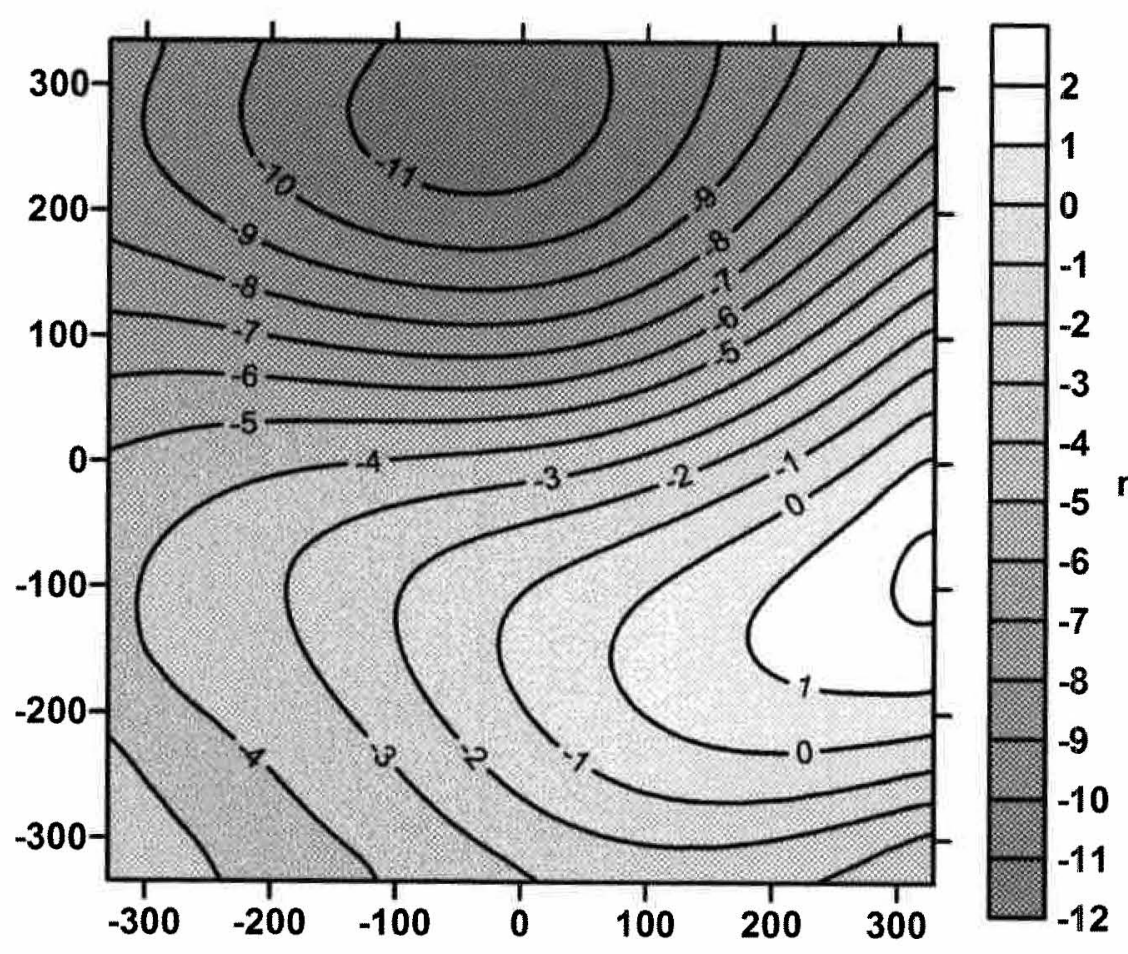

Laplace distribution, Simplex method

Gaussian distribution, Simulated annealing method
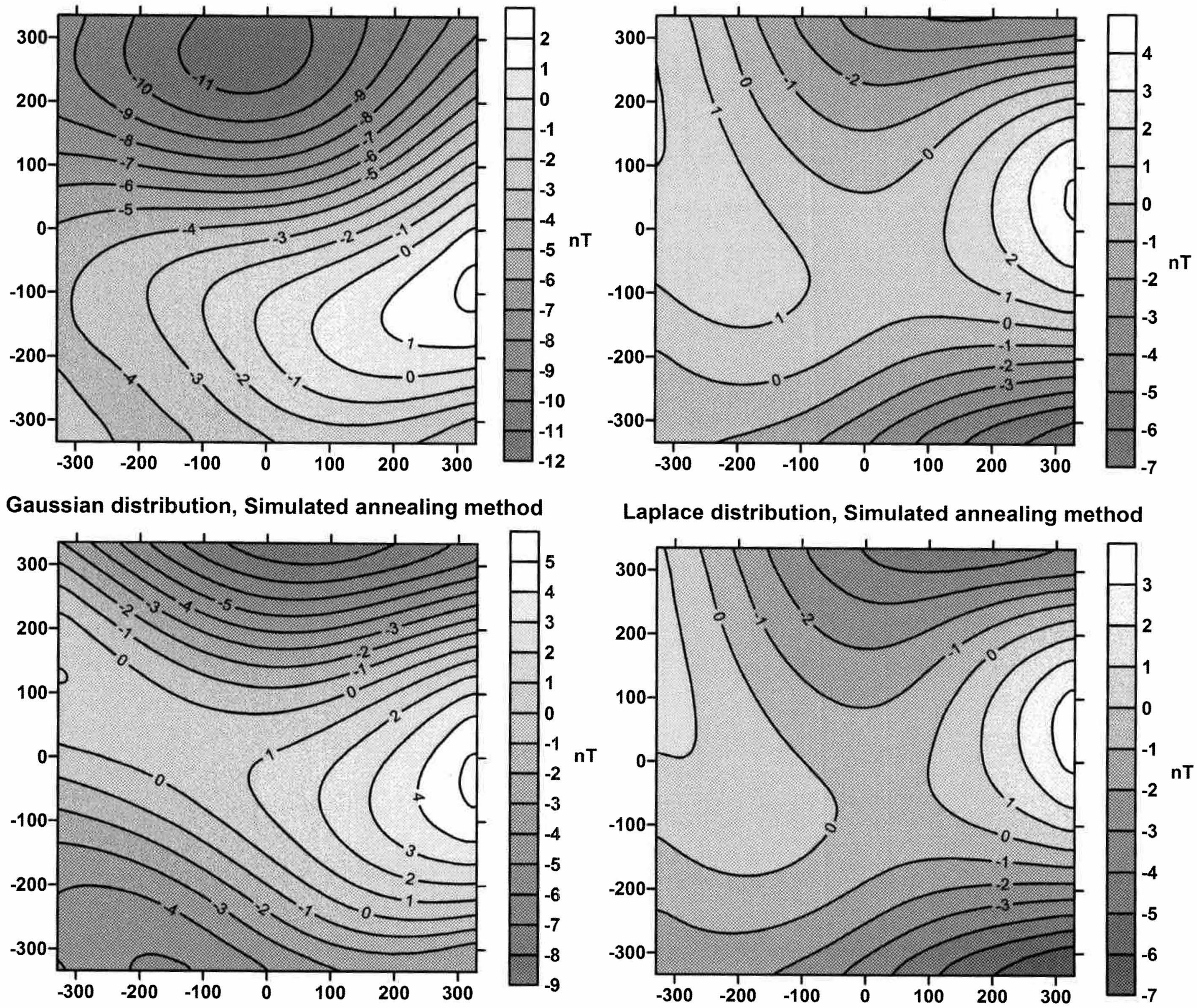

Laplace distribution, Simulated annealing method

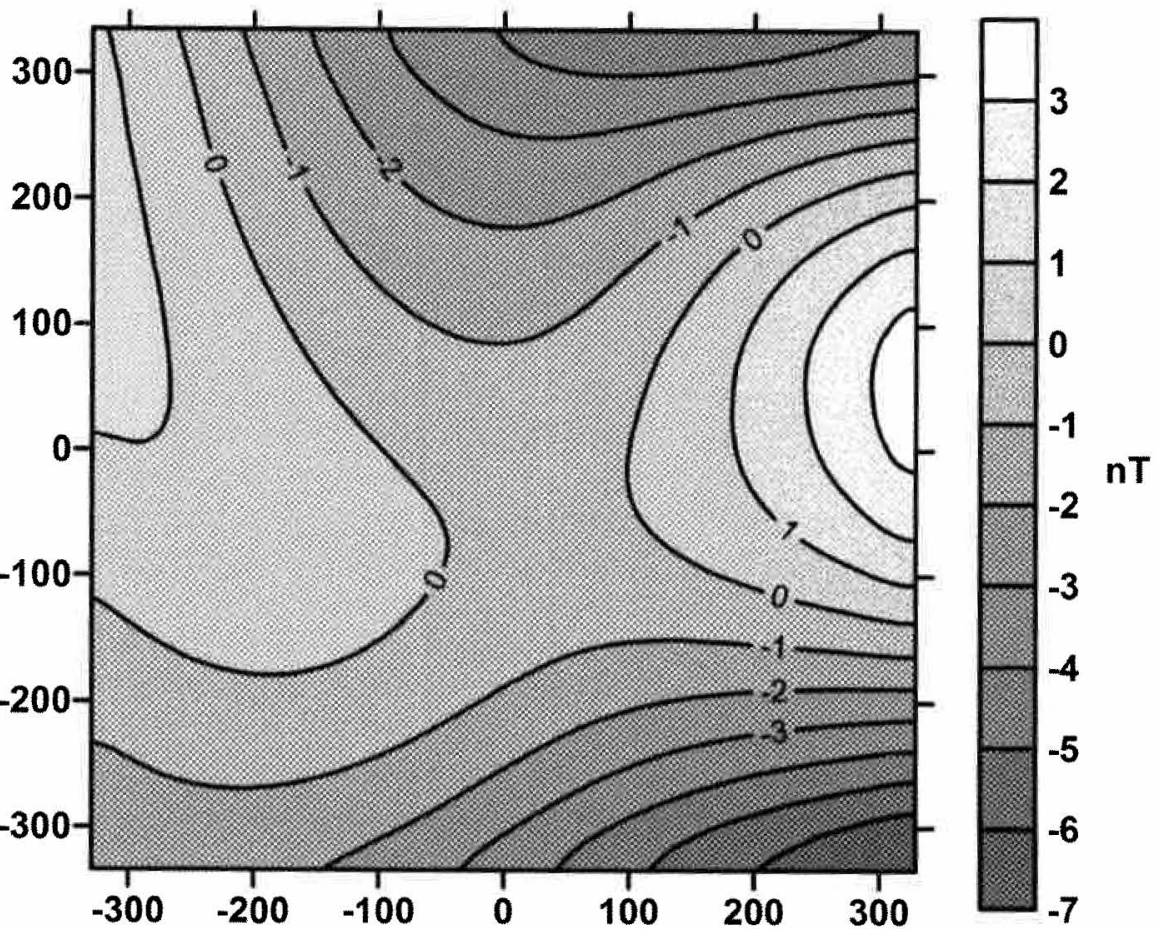

